\title{
A RARE CASE OF VULVAL FIBROID DURING PREGNANCY PRESENTING LIKE BARTHOLIN'S ABSCESS
}

KEY WORDS: Vulval Fibroid,

Bartholin's Cyst

\section{Dr. Sonu Kumar Batham*}

MBBS, MS, Obstetrics \& Gynecology, Assistant Professor, Department of Obstetrics \& Gynecology, Chhindwara Institute of Medical Sciences, Chhindwara, M.P. 480001.*Corresponding Author

Introduction: - Fibroid are commonly found in uterus and cervix but rarely may found other sites (broad ligament, ovary, Vulva, vagina etc). Here we are presenting a rare case of Vulval Fibroid.

Case Report: - A 25 years old woman G4P3L3 with 37 weeks pregnancy presented to OPD with complaint of severe pain at perineal region. There was history of fall in bathroom 1 month ago. On examination there was a swelling at right vulvovaginal junction of $4 \times 4 \mathrm{~cm}$, (probably bartholin cyst) with firm smooth surface, with no signs of acute inflammation, for that Incision and drainage was done and an organized mass was resected out. On histopathlogical examination, it was found to be a leiomyoma with myxoid degeneration.

Discussion :- fibroids rarely presents with pain and inflammation and on the other hand bartholin's cyst or abscess mostly presents with pain and inflammation, so detailed history and examination with broad suspicion are the keys to differentiate between Bartholin's cyst and vulval fibroids.

\section{INTRODUCTION}

Bartholin Abscess is a common female genital complaint during reproductive age. Usually diagnosis is made by clinical findings and typical presentation, but sometimes signs and symptoms get concealed by anti-inflammatory and antibiotics use. On the other hand most of the fibroids do not present with malignant features, pregnancy can have a variable and unpredictable effect on fibroid growth. Here we present a rare case of vulval fibroid that presented like a Bartholin's Abscess that was diagnosed only after surgical removal and histopathology examination.

\section{Case Report}

A 25 years old woman G4P3L3 with 37 weeks pregnancy presented to Obstetrics OPD at ESIC Medical College and Hospital, Faridabad-121001, India with chief complaint of severe pain at perineal region for last 15 days. There was history of fall in bathroom while taking bath 1 month ago, with impact on perineum, and patient thought that the pain was due to that perineal injury. After the pain not getting relieved, she visited some medical practitioner and also got admitted in some government hospital for 7 days where she received systemic antibiotics and anti-inflammatory drugs about for 5 days, possibly treated for Bartholin's Abscess/organized hematoma. Pain got relieved to some extend after taking these drugs.

There was no significant past history of similar infection or perineal swelling in past, no history of diabetes, severe pelvic inflammatory disease or any other chronic illness. Woman belonged to middle socioeconomic group family and lived in a metro city. She did not give any history of drug abuse or alcoholism.

On examination, patient was in excruciating pain and hardly allowed to examine at the painful perineal site. The swelling was localized at right vulvo-vaginal junction (at the site of the Bartholin's cyst), about $4 \times 4 \mathrm{~cm}$ in size, with firm smooth surface, with no signs of acute inflammation or pus point. Per abdominal examination revealed gravid uterus of 36 weeks size with cephalic presentation, longitudinal lie, no uterine contraction, no deformity, and with normal fetal heart sounds. On perspeculum examination, there were no signs of any infection or leaking, and cervix was found to be healthy and parous.

Her hemoglobin was $10.5 \mathrm{gm} / \mathrm{dl}$, WBC- 6900/dl, platelets$1.47 \mathrm{lacs} / \mathrm{dl}$, Blood group - O positive, RBS- $76 \mathrm{mg} / \mathrm{dl}$, serum creatinine- $0.6 \mathrm{mg} / \mathrm{dl}$, bleeding time- 03 minutes 25 seconds, clotting time 04 minutes 30 seconds. Her previous obstetric sonography was suggestive of single live intra-uterine fetus with cephalic presentation; placenta was present at anterior upper location with adequate amount of liquor and effective fetal weight of 1496 grams. We performed transvaginal sonography of the patient which was hardly suggestive of Bartholin's Abscess.

The patient was admitted in labour room and marsupialization or cystectomy was planned, but due to persistent severe pain, patient was taken for emergency Incision and Drainage. She was positioned in dorsal position, cleaned and draped, and Lignocaine local anesthesia was administered at right vulva. After local anaesthesia, pain was relieved and patient allowed to thoroughly examination of swelling which is usually not seen in Bartholin's Abscess where local anaesthesia is generally not much effective. Incision was given at most prominent part of swelling but no pus was drained and after going to some more depth than that for usual Bartholin's, we found a smooth, pebbled surfaced mass that was easily resected out from its attachments. After achieving haemostasis, the wound was closed with intermittent sutures and the mass was sent for histopathological examination. Following this procedure patient was absolutely relieved of pain and was discharged from the hospital in stable condition. After two weeks, patient delivered vaginally without any complication.

In histopathology report, a globular grey white soft tissue piece measuring $2 \times 2 \times 1.5 \mathrm{~cm}$ was found on gross examination (picture 1).On cut section, there was homogenous grey white tissue picture 2. On microscopic examination, a leiomyoma with myxoid degeneration was found. Thus, this was a rare case of vulval fibroid which also presented with a very rare complication of myxomatous degeneration.

\section{DISCUSSION-}

Fibroids or leiomyomas are benign, monoclonal tumors of smooth muscle cells, very commonly seen in the uterus and rarely found in other sites like broad ligament, ovaries, vulva and urethra or any other anatomic site ${ }^{1}$. Increasing number of parity decreases the incidence and number of clinically apparent fibroids ${ }^{2}$. Incidence of symptomatic fibroids is comparatively less during pregnancy ${ }^{3}$. Even risk of growing new fibroid is lower among women with more recent pregnancies than with remote pregnancies. External genital fibroids are extremely rare and usually mimic a Bartholin cyst or abscess. ${ }^{4}$ Vulval fibroid itself rarely presents with severe pain ${ }^{5}$.Whereas, Bartholin's Abscess are more common in pregnancy and mostly present with pain and difficult intercourse. ${ }^{6,7}$ Pain in this case report might be because of degenerative changes in fibroid, usually pain presents in large fibroids $(>5 \mathrm{~cm}$ ) when size outgrow their blood supply. Pain is the most common complication of fibroids in 
pregnancy, and is seen most often in second and third trimesters of pregnancy. ${ }^{8,9}$ In a study $9 \%$ of fibroids showed cystic changes on ultrasound indicating the development of red degeneration, that results in a change in the architecture (kinking) of the blood supply to the fibroid leading to ischemia and necrosis even in the absence of fibroid growth. ${ }^{10}$ according to another theory, pain results from the release of prostaglandins from cellular damage within the fibroid. The pain of a degenerating fibroid is often localized at the site of the fibroid and can last up to two weeks, the degenerative changes, can be of several forms, these are red degeneration, hyaline, cystic and myxoid, in this presented case degeneration was of myxoid type that might be a cause of very severe pain and simulated as Bartholin abscess. So detailed history and examination are the keys to differentiate between Bartholin's cysts or abscess from other rarer vulval diseases. ${ }^{11}$ If there is vulval swelling with firm consistency, vulval fibroid should be a differential diagnosis ${ }^{12}$. On initial presentation most of the vulval leiomyoma are usually misdiagnosed as Bartholin's cyst or abscess ${ }^{13-15}$. In our case also features were suggestive of Bartholin's abscess initially. Surgical excision with histopathological confirmation and follow up is the treatment of choice for vulval fibroids.

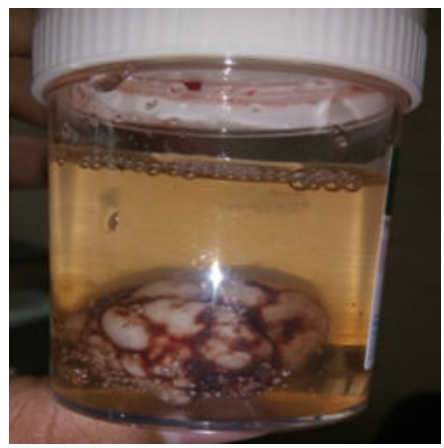

Figure - 1: Gross picture of Vulval Fibroid

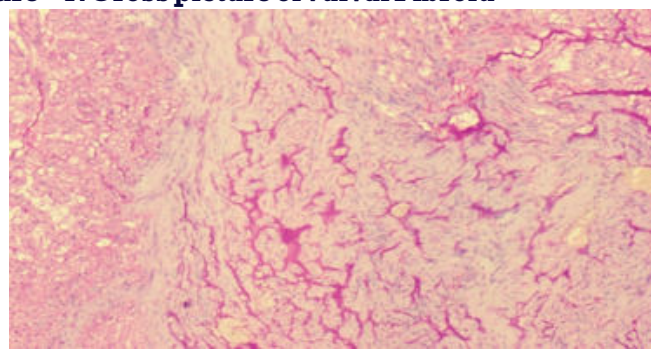

Figure-2: Microscopic view of fibroid showing interlacing smooth muscle bundles with interspersed myxoid matrix

\section{CONCLUSION}

Leiomyoma of vulva is a very rare condition and is usually misinterpreted as Bartholin cyst or abscess, It should be kept as a differential diagnosis when a woman presents with pain and unilateral swelling in vulvar region which is firm in consistency.

\section{REFERENCES}

1. Fasih N, Prasad Shanbhogue AK, Macdonald DB, Fraser-Hill MA, Papadatos D, Kielar AZ, et al. Leiomyomas beyond the uterus: Unusual locations, rare manifestations. Radiographics. 2008;28:1931-48.

2. Wise LA, Palmer JR, Harlow BL, et al. Reproductive factors, hormonal contraception, and risk of uterine leiomyomata in African-American women: a prospective study. Am JEpidemiol 2004;159:113-23.

3. H. Lee, E. R. Norwitz, and J. Shaw, "Contemporary management of fibroids in pregnancy,"Reviews in Obstetrics Gynecology,vol.3, no. 1, pp. 20-27, 2010.

4. Levy RA,WinhamWM, Bryant CS, Quick CM. Smooth muscle neoplasms of the vulva masquerading as Bartholin gland duct cysts. Proc (Bayl Univ Med Cent). 2014;27(1):25-7.

5. ChakrabartiI,De A,Pati S.Vaginal leiomyoma.JMidlife Health. 2011;2(1):42-43.

6. Lee MY, Dalpiaz A, Schwamb R, MiaoY, Waltzer W, Khan A. Clinical pathology of Bartholin's glands: A review of the literature. Curr Urol 2015;8:22-5.

7. Omole F, Simmons BJ, Hacker Y. Management of Bartholin's duct cyst and gland abscess. Am Fam Physician 2003;68:135-40.

8. Burton CA, Grimes DA, March CM. Surgical management of leiomyomata during pregnancy. Obstet Gynecol. 1989;74:707-709.

9. Katz VL ,Dotters DJ, Droegemueller W. Complications of uterine leiomyomas in pregnancy. Obstet Gynecol. 1989;73:593-596.

10. Parker WH. Etiology, symptomatology, and diagnosis of uterine myomas. Fertil Steril. 2007:87:725-736

11. Deeksha Pandey, Jyothi Shetty, Aashish Saxena, and P.S. Srilatha, "Leiomyoma in Vulva:A Diagnostic Dilemma," Case Reports in obstetrics and Gynecology, vol.2014, Article ID 386432,3 pages, 2014

12. SAXENA, Shilpi; GOEL, Suyash; SEN, Alok D.. Leiomyoma of the vulva: a diagnostic challenge. International Journal of Reproduction, Contraception, Obstetrics and Gynecology, [S.1.], v. 7,n.3,p. 1246-1248, feb.2018.

13. S.A. Francis, F.L. Wilcox, and M. Sissons. Bartholin's gland liomyoma: a diagnostic and management dilemma. Journal of Obsterics and Gynaecology Research, vol.38, no.6,pp.941-943,2012.

14. Youssef A, Neji K, barki MM, Ben Amara F, Malek M, Rziga H. Leiomyoma of the vulva.La Tunisie Medicale. 2013;91(1):78-80.

15. Zhao T, Liu X, LuY. Myxoid Epithelial Leiomyoma of the Vulva: A Case Report and Literature Review. Case Rep Obstet Gynecol. 2015;2015:894830. 